\title{
Development of a Flow Field for Testing a Boundary-Layer- Ingesting Propulsor
}

\author{
Stefanie M. Hirt, ${ }^{1}$ David J. Arend, ${ }^{2}$ and John D. Wolter ${ }^{3}$ \\ NASA Glenn Research Center, Cleveland, Ohio, 44135 \\ and \\ Aaron Johnson ${ }^{4}$ \\ Jacobs Technology, Cleveland, OH, 44135
}

\begin{abstract}
The test section of the 8- by 6-Foot Supersonic Wind Tunnel at NASA Glenn Research Center was modified to produce the test conditions for a boundary-layer-ingesting propulsor. A test was conducted to measure the flow properties in the modified test section before the propulsor was installed. Measured boundary layer and freestream conditions were compared to results from computational fluid dynamics simulations of the external surface for the reference vehicle. Testing showed that the desired freestream conditions and boundary layer thickness could be achieved; however, some non-uniformity of the freestream conditions, particularly the total temperature, were observed.
\end{abstract}

\section{Nomenclature}

$\begin{array}{lll}8 \times 6 \mathrm{SWT} & = & 8-\text { by } 6-\text { Foot Supersonic Wind Tunnel } \\ \mathrm{BL} & = & \text { Boundary Layer } \\ \mathrm{BLI} & = & \text { Boundary Layer Ingesting } \\ \mathrm{BWB} & = & \text { Blended Wing Body } \\ \mathrm{CFD} & = & \text { Computational Fluid Dynamics } \\ \mathrm{TS} & = & \text { Tunnel Station, in } \\ h & = & \text { height of the boundary layer thickening pins, in } \\ u & = & \text { velocity in the streamwise direction, } \mathrm{ft} / \mathrm{s} \\ U_{\infty} & = & \text { freestream velocity in the streamwise direction, } \mathrm{ft} / \mathrm{s} \\ x & = & \text { axial coordinate, tunnel station, in } \\ y & = & \text { transverse coordinate, in } \\ z & = & \text { vertical coordinate, in } \\ \delta & = & \text { boundary layer thickness (99\% of the freestream velocity), in }\end{array}$

\section{Introduction}

variety of next-generation vehicle configurations employing boundary-layer-ingesting (BLI) propulsion systems A are being investigated ${ }^{1-3}$. One such configuration is the hybrid wing body vehicle shown in Fig. 1. A system study of this configuration showed that BLI propulsion had the potential to reduce vehicle fuel burn by 3 - $5 \%$ relative to a baseline propulsion system ${ }^{4}$.

\footnotetext{
${ }^{1}$ Aerospace Engineer, Inlets and Nozzles Branch, Mail Stop 5-12, 21000 Brookpark Rd, Senior Member AIAA.

${ }^{2}$ Aerospace Engineer, Inlets and Nozzles Branch, Mail Stop 5-12, 21000 Brookpark Rd, Associate Fellow AIAA.

${ }^{3}$ Aerospace Engineer, Inlets and Nozzles Branch, Mail Stop 5-12, 21000 Brookpark Rd, Associate Fellow AIAA.

${ }^{4}$ Mechanical Test Engineer, 21000 Brookpark Rd, Cleveland, OH 44135, Member.
} 


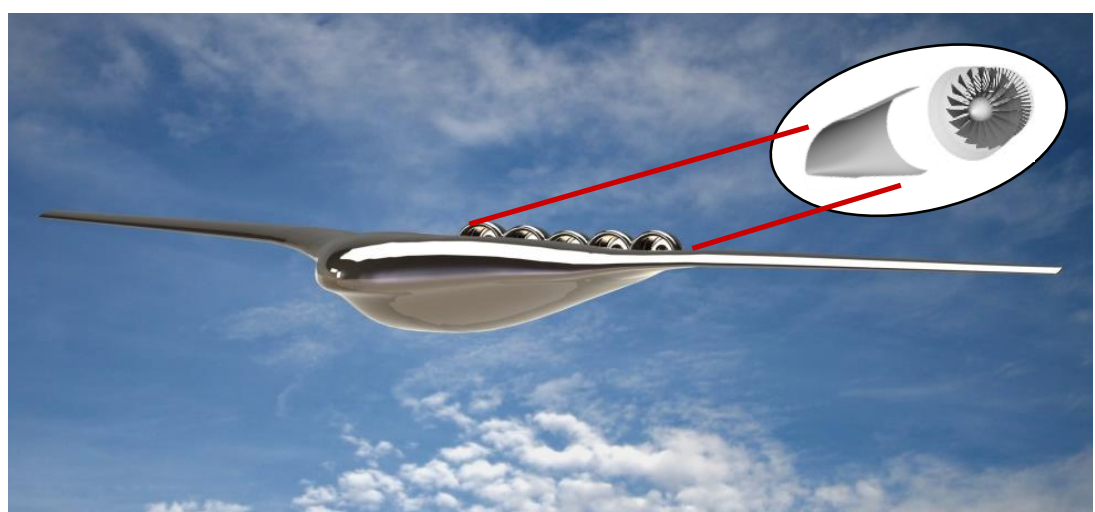

Figure 1. Hybrid wing body vehicle with boundary layer-ingesting propulsion.

For these benefits to be realized, the BLI propulsor would need to be able to operate in a highly-distorted flow environment while maintaining acceptably high levels of performance and operability. A closely-coupled inlet/fan system was designed for this purpose ${ }^{5-7}$. To test this design, a test entry was planned ${ }^{8}$ in the 8- by 6-Foot Supersonic Wind Tunnel at NASA Glenn Research Center.

Because of the embedded-propulsion configuration, modifications to the tunnel test section were required. These modifications included a raised false floor with a bleed region incorporated, creating a new 6.5- by 6-Foot Transonic BLI propulsor test bed configuration. Due to the extent of the modifications a new calibration of the test section was required to measure the flow properties that would be entering the propulsor. This paper describes the desired inflow for the propulsor, the wind tunnel modifications required to produce that inflow, and the results of the wind tunnel test to measure and calibrate the flow properties of the modified test section.

\section{Experimental Setup}

\section{A. Facility Description}

This test was conducted in the 8- $x$ 6-Foot Supersonic Wind Tunnel ${ }^{9}$ (8x6 SWT) located at the NASA Glenn Research Center. The 8x6 SWT is an atmospheric-pressure, continuous-flow wind tunnel with a $23 \mathrm{ft}$, 6 in long constant area test section. The test section has two regions: a $9 \mathrm{ft}, 1$ in long, solid-wall, supersonic flow region followed by a $14 \mathrm{ft}, 5$ in long, porous-wall, transonic region. Plugs are available to fill the porosity holes and tailor the tunnel porosity depending on the needs of the test. For this test, all of the porosity holes were open. Figure 2 shows a sketch of the test section region of the 8x6 SWT.

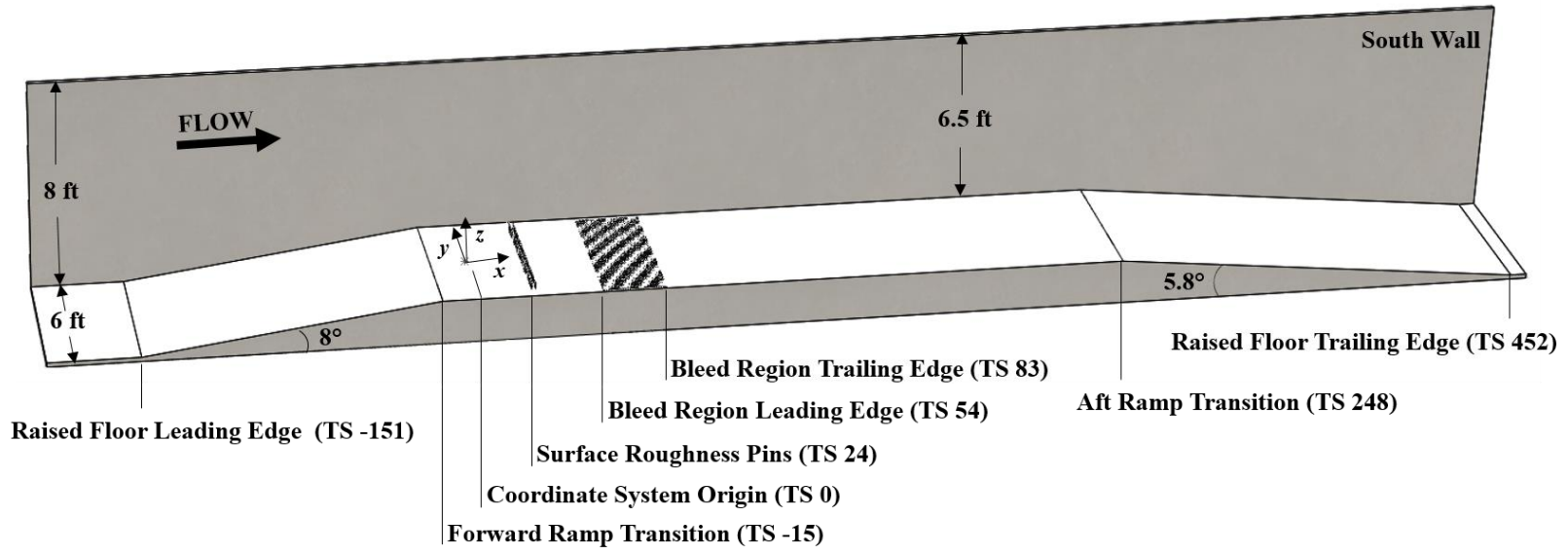

Figure 2. Sketch of the test section region of the 8x6 SWT as configured for this calibration test entry, with the top and north walls removed from view.

The Mach number range in the transonic test section is 0.25 to 2.0 for standard operation. For this test, the flexible walls that form the tunnel nozzle for supersonic operation were locked in the flat position for subsonic operation, and Mach number was set by controlling the compressor speed. For a given set of test section conditions, the balance 
chamber pressure, which controls the amount of test section bleed, and the shock door (second throat) position also needed to be set appropriately. The data presented in this paper were collected with the tunnel in its aerodynamic, closed-loop cycle.

The coordinate system origin for this test was chosen such that the axial direction is represented by $x$ with the origin - tunnel station 0 - located 0.5 in downstream of the test section/flexwall seam and magnitude increasing in the downstream direction. The spanwise direction is represented by $y$ with the origin at the tunnel centerline and magnitude increasing toward the south wall. The vertical direction is represented by $z$ with the origin at the surface of the raised floor and the magnitude increasing toward the tunnel ceiling.

\section{B. Defining Desired Inflow Conditions}

In 2006, NASA defined a series of aircraft system level goals to drive technology advancement. Growing out of these goals, a number of research efforts were initiated including research into the blended wing body (BWB) vehicle configuration and embedded BLI propulsion. The BWB vehicle concept was seen as a platform conducive to the integration of BLI propulsion, and a decision was made to align these efforts such that the Boeing N2A-exte BWB ${ }^{1}$ became the reference vehicle for NASA's BLI propulsion test effort.

A system study performed by United Technologies Research Center (UTRC) looking at the effects of boundary layer ingestion on this vehicle concept showed that in order to obtain the greatest benefits, the inlets needed to be aft of $80 \%$ of the vehicle length and needed to span the width of the aft body ${ }^{4}$. Computational fluid dynamics (CFD) solutions were generated for the flight-scale external vehicle geometry with no propulsion modeled, and these solutions were used to define the desired inflow conditions for the propulsor.

Based on a combination of the expected inlet location identified by the system study and the experiment sizing constraints in the $8 \times 6$ SWT, the flow conditions at a location of $80 \%$ of the vehicle length were selected to be matched in the experiment. This location is upstream of the external diffusion effects generated by the inlet. The normalized boundary layer profile from the CFD at the match location is shown in Fig. 3. Scaling this profile geometrically to the wind tunnel experiment scale resulted in a desired boundary layer thickness of $4.8 \mathrm{in.} \mathrm{Based} \mathrm{on} \mathrm{the} \mathrm{CFD} \mathrm{solutions} \mathrm{and}$ the wind tunnel capabilities, the freestream conditions targeted in the wind tunnel test were as shown in Table 1.

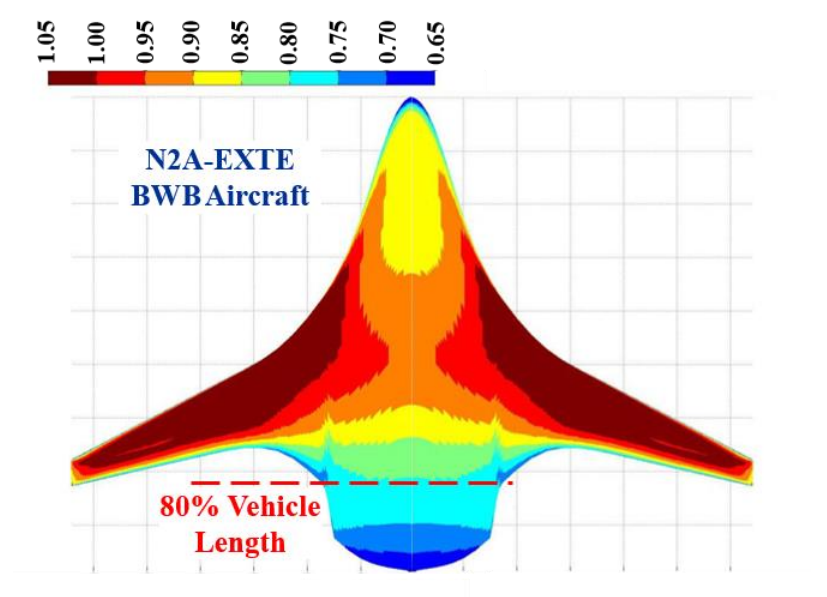

(a)

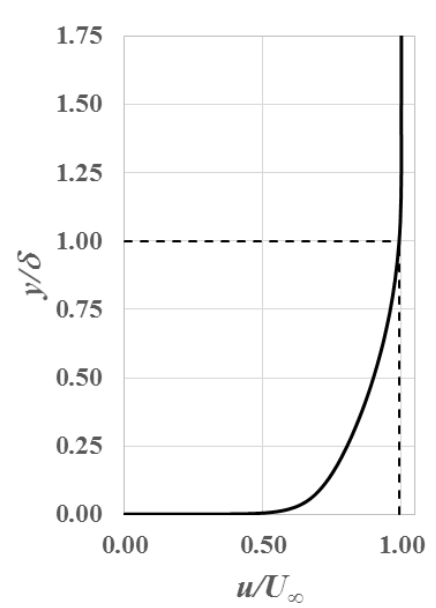

(b)

Figure 3. Results from CFD of external aircraft flowfield. (a) Normalized static pressure on the vehicle surface. The location at which the target boundary layer was extracted is marked. (b) Normalized boundary layer profile at $80 \%$ of the vehicle length.

Table 1. Target tunnel freestream conditions.

\begin{tabular}{l|r} 
Mach Number & 0.78 \\
\hline Total Pressure & $16.9 \mathrm{psia}$ \\
\hline Total Temperature & $560 \mathrm{R}$ \\
\hline Reynolds Number & $4.47 \times 10^{6} 1 / \mathrm{ft}$
\end{tabular}




\section{Test Specific Hardware}

In order to simulate the representative conditions for a boundary-layer-ingesting propulsor as described above, test hardware was developed to allow for matching the freestream and boundary layer flow conditions. On the reference vehicle, the engine is installed embedded into the trailing edge of the fuselage. To duplicate the installation and most-easily accommodate using the fan drive rig, the propulsor needed to be installed along the floor of the wind tunnel. Because the porous wall of the 8x6 SWT did not allow for the fan model to be embedded, a raised false floor was designed in which to embed the propulsor. To thicken the boundary layer, an array of pins was used. Additionally, to allow for adjustability of the boundary layer during testing, a bleed system was developed.

An overview of the test hardware is shown in Fig. 4. The raised floor, boundary layer-thickening pins, and raised floor bleed system are described in more detail in this section.

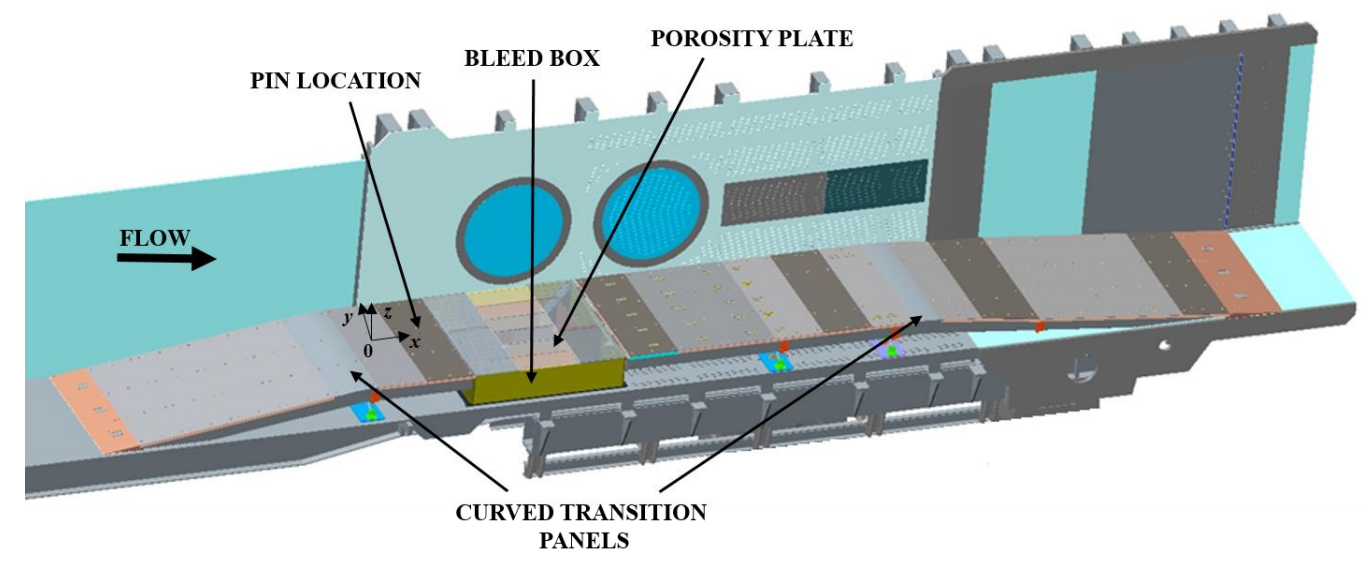

Figure 4. Image of the test hardware installed in the 8x6 SWT.

\section{Raised Floor}

The raised floor was designed to provide the required flowfield entering the propulsor. It stretched $50 \mathrm{ft}, 3 \mathrm{in}$, rising from the floor of the wind tunnel at an $8^{\circ}$ angle to a height of 18 in above the tunnel floor, continued horizontally for a distance of $22 \mathrm{ft}$, then sloped back to the tunnel floor at a $5.8^{\circ}$ angle. The horizontal section created the new test section region, which began at tunnel station -15.254 and extended to tunnel station 248.408. Curved panels that matched the first derivative and approximately matched the second derivative of the surface contour were used where the slope transitioned to smoothly guide the flow. Photographs of the raised floor installed in the 8x6 SWT along with its internal structure are shown in Fig. 5.

The surface of the floor consisted of a series of panels designed to be replaceable to allow for configuration changes. Seals were used between the panels as well as below the 0.125 in gap on either edge of the panels along the tunnel sidewalls to prevent flow between the upper and lower surfaces of the raised floor. The panels were carefully leveled during installation to minimize steps. Measurements of the installed raised floor showed that steps in the flow surface were kept below 0.010 in forward-facing and 0.030 in rear-facing.

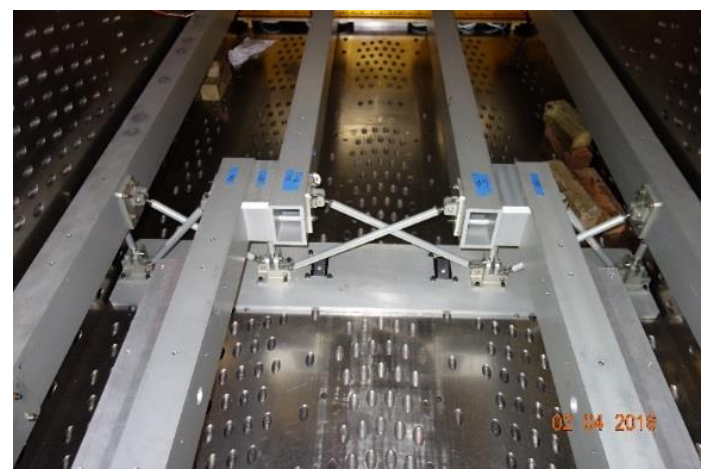

(a)

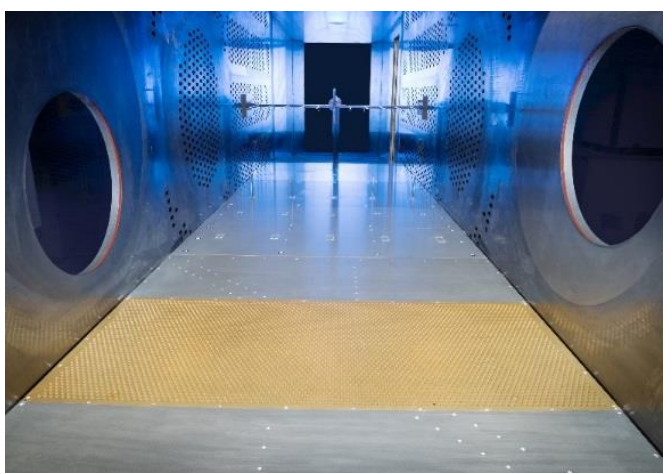

(b)

Figure 5. (a) Photograph of the structure of the raised floor prior to the installation of the aerodynamic raised floor surface panels. (b) Photograph of the assembled raised floor, looking from upstream to downstream. 


\section{Boundary Layer Thickening Pins}

Having the desired boundary layer thickness entering the propulsor was critical for proper simulation fidelity. Initial CFD solutions of the raised floor configuration showed that the boundary layer developed over the raised floor was slightly thinner than was required to match the reference vehicle. In order to get to that match, a set of boundary layer thickening pins was designed based on the work of Otten ${ }^{10}$ which showed that two parallel rows of alternately spaced cylindrical pins could be used to produce thick turbulent boundary layer profiles.

The flow conditions in this test were similar to those described in Otten's work in terms of Mach and Reynolds numbers, but the boundary layer approaching the pins was thicker for this experiment. To address the discrepancy in incoming boundary layer thickness, additional CFD cases with gridded pins were run to assess the efficacy of the pins under the test conditions. The CFD solutions indicated that pins would effectively thicken the boundary layer for the test flow conditions, and these results guided the final pin design.

The pins were arranged in two staggered rows spanning the tunnel as shown in Fig. 6. The upstream row of pins was located at tunnel station 24, near the beginning of the horizontal section of the raised floor, and consisted of 31 pins spaced 2 in apart with the $16^{\text {th }}$ pin at the tunnel centerline. This row covered a total width of 60 in leaving 6 in by each tunnel sidewall without pins. The second row contained 30 pins located 1.732 in aft of the first row.

The pins were solid cylinders with a 0.25 in diameter and a $45^{\circ}$ bevel 0.02 in deep around the end. Three pin heights were selected to be built to provide flexibility during testing. It was understood that longer pins would provide greater thickening of the boundary layer. The pin heights that were available for testing were $1.50 \mathrm{in}, 2.00 \mathrm{in}$, and 2.75 in.

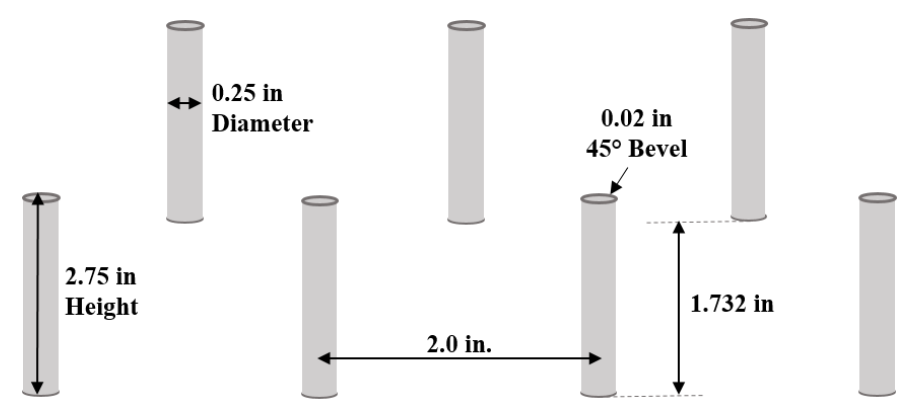

(a)

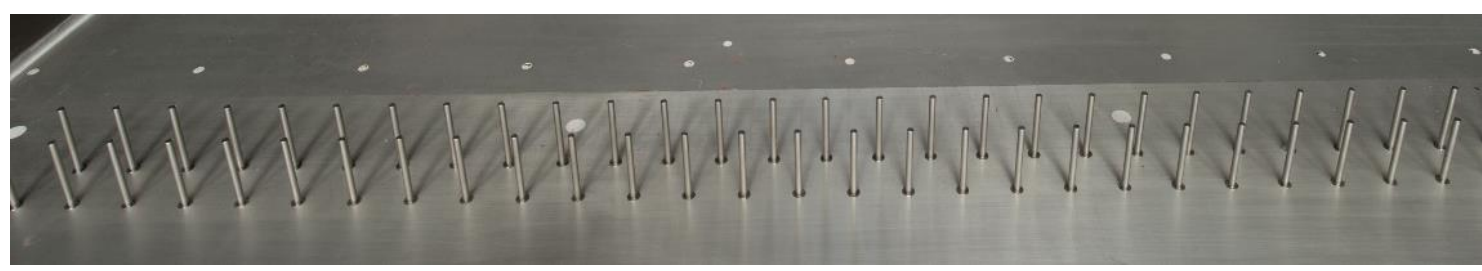

(b)

Figure 6. (a) Schematic and (b) Photograph of the boundary layer thickening pins installed in the raised floor.

\section{Raised Floor Bleed System}

In order to be able to adjust the boundary layer thickness during testing, a bleed system was designed and incorporated into the raised floor. The bleed system was comprised of a perforated panel that allowed air to be pulled into a bleed box between the raised floor and the tunnel floor, which channeled the flow through the lower plenum and into the pipes that connect to the facility exhaust system through the exhaust collector. An overall view of the bleed system is shown in Fig. 7. 


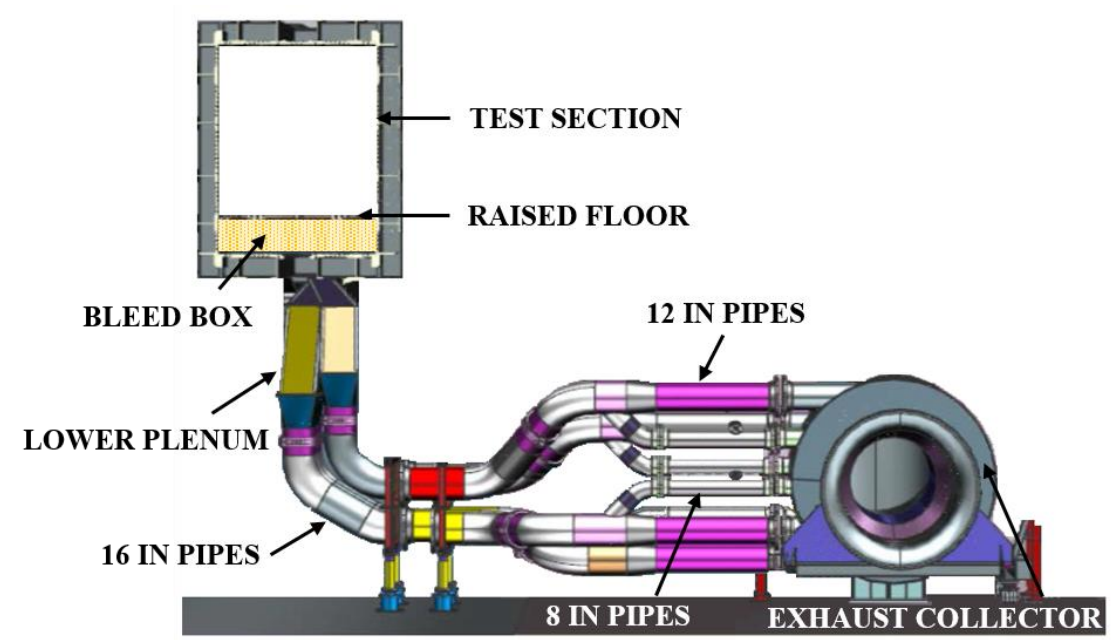

Figure 7. View of the raised floor bleed system installed in the 8x6 SWT showing a cut through the test section (flow direction out of the page) and the bleed system exhaust plumbing installed below the tunnel floor.

The porosity plate for the raised floor bleed was located downstream of the flow conditioning pins. The porous region stretched from tunnel station 54.235 to tunnel station 82.505 and was perforated with 0.50 in diameter holes to provide $40 \%$ porosity. The width of the porous region was 68.264 in leaving 1.868 in along each tunnel sidewall without bleed, which was as close as possible with the structure below. The porosity plate is shown in Fig. 8(a).

The flow through the porous plate was pulled into the bleed box, which was segmented into six compartments. This created six distinct bleed regions wich could be controlled individually to allow variation of the bleed rate across the span of the tunnel if necessary to produce a uniform boundary layer in the spanwise direction. Turning vanes were used to guide the flow through the bleed box and down into the lower plenum. A photograph of the bleed box during installation is shown in Fig. 8(b).

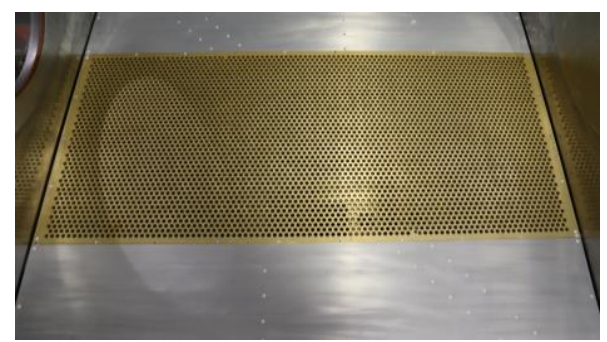

(a)

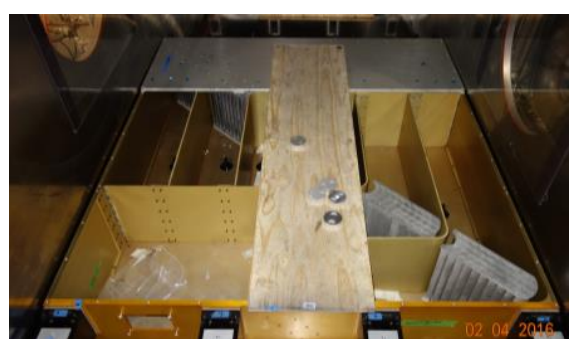

(b)

Figure 8. Photographs of the bleed system (a) porosity plate and (b) bleed box during installation.

The lower plenum carried the bleed flow through the tunnel floor and into a series of six 16 in pipes, one for each bleed region. Each 16 in pipe was then divided into an 8 in and a 12 in pipe. The 8 in lines included butterfly control valves that allowed for fine control of the bleed flow rate in order to make small adjustments of the boundary layer thickness. This allowed the boundary layer thickness to be adjusted to the desired value as well as testing the sensitivity of the propulsor to variations in boundary layer thickness. The 12 in lines included a valve that was configured to be either full open or full closed. This provided the ability to dramatically reduce the boundary layer thickness if necessary to reduce the loading on the fan to aid in either getting out of or passing through a high stress condition. The six 8 in lines and the six 12 in lines connected to the outer annulus of the exhaust collector. The exhaust collector connected both the raised floor bleed and the bleed through the tunnel porosity to NASA Glenn Research Center's high flow vacuum piping system.

\section{Instrumentation}

To understand the effects that the new test hardware has on the wind tunnel flowfield, a calibration test was conducted with the new hardware. This section describes the instrumentation that was used to measure the flow properties in the modified wind tunnel test section. 
For the instruments described, the accuracy of the pressure transducers was $\pm 0.0075 \mathrm{psi}$ for absolute pressure levels. The measurement uncertainty for the flow angularity data is $\pm 0.15^{\circ}$. The accuracy in the total temperature measurements is $\pm 1.8 \mathrm{R}$.

\section{Facility instrumentation}

Pre-existing instrumentation in the $8 \times 6$ SWT facility was used to measure the pressure and temperature entering the test section, the static pressure along the tunnel walls, and the balance chamber conditions. To measure the incoming flow properties, a pair of bellmouth rakes was installed on the north and south walls of the tunnel near the exit of the bellmouth upstream of the test section. Figure 9 shows a photograph of the bellmouth rakes. Each bellmouth rake had five total pressure and two total temperature measurements, which were averaged to define the inflow conditions. For this test, the bellmouth rakes were modified to add Kiel shields ${ }^{11}$ to the thermocouples.

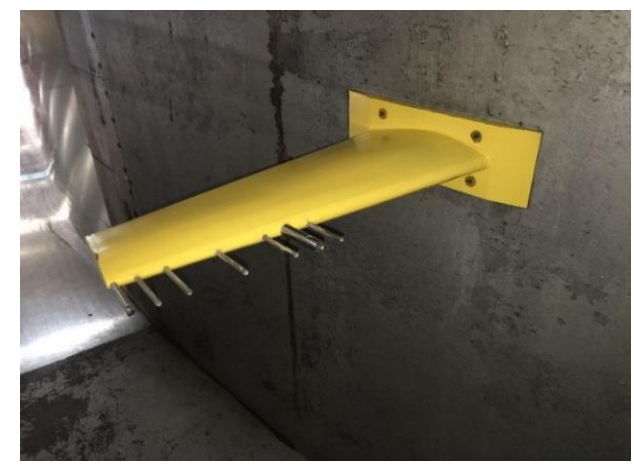

Figure 9. Photograph of one of the facility bellmouth rakes.

\section{Raised Floor Instrumentation}

A total of 180 static taps provided information on the development of the flowfield over the raised floor. There were a total of 26 axial stations of static pressure measurements. The locations of the static taps are listed in Table 2. It can be seen that generally each raised floor panel has 6 static taps arrayed laterally. In addition, just upstream and downstream of the raised floor bleed there are stations with 18 static taps, rows numbered 10 and 11 in Table 2. In addition to the static taps along the surface of the raised floor, there were nine pressure measurements in the plenum created between the lower surface of the raised floor and the wall of the 8x6 SWT to allow for monitoring of the pressure differential across the raised floor. 
Table 2. Locations of the Raised Floor Static Taps.

\begin{tabular}{|c|c|c|c|c|c|c|c|}
\hline \multirow{2}{*}{ Row } & \multirow{2}{*}{$\begin{array}{l}\text { Tunnel } \\
\text { Station }\end{array}$} & \multicolumn{6}{|c|}{ Static Tap $y$ locations } \\
\hline & & Line 1 & Line 2 & Line 3 & Line 4 & Line 5 & Line 6 \\
\hline 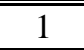 & -139.111 & -30 & -18 & -6 & 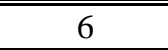 & 18 & 30 \\
\hline 2 & -117.729 & -30 & -18 & -6 & 6 & 18 & 30 \\
\hline 3 & -93.963 & -30 & -18 & -6 & 6 & 18 & 30 \\
\hline 4 & -70.269 & -30 & -18 & -6 & 6 & 18 & 30 \\
\hline 5 & -46.43 & -30 & -18 & -6 & 6 & 18 & 30 \\
\hline 6 & -25.501 & -30 & -18 & -6 & 6 & 18 & 30 \\
\hline 7 & -4.254 & -30 & -18 & -6 & 6 & 18 & 30 \\
\hline 8 & 18.75 & -30 & -18 & -6 & 6 & 18 & 30 \\
\hline 9 & 42.562 & -28.75 & -17.25 & -5.75 & 5.75 & 17.25 & 28.75 \\
\hline 10 & 49.875 & $\begin{array}{l}1:-34.105 \\
2:-30.105 \\
3:-26.105\end{array}$ & $\begin{array}{l}4:-22.105 \\
5:-18.105 \\
6:-14.105\end{array}$ & $\begin{array}{c}7:-10.105 \\
8:-6.105 \\
9:-2.105\end{array}$ & $\begin{array}{c}10: 2.105 \\
11: 6.105 \\
12: 10.105\end{array}$ & $\begin{array}{l}13: 14.105 \\
14: 18.105 \\
15: 22.105\end{array}$ & $\begin{array}{l}16: 26.105 \\
17: 30.105 \\
18: 34.105\end{array}$ \\
\hline 11 & 87.393 & $\begin{array}{l}1:-34.105 \\
2:-30.105 \\
3:-26.105\end{array}$ & $\begin{array}{l}4:-22.105 \\
5:-18.105 \\
6:-14.105\end{array}$ & $\begin{array}{c}7:-10.105 \\
8:-6.105 \\
9:-2.105\end{array}$ & $\begin{array}{c}10: 2.105 \\
11: 6.105 \\
12: 10.105\end{array}$ & $\begin{array}{l}13: 14.105 \\
14: 18.105 \\
15: 22.105\end{array}$ & $\begin{array}{l}16: 26.105 \\
17: 30.105 \\
18: 34.105\end{array}$ \\
\hline 12 & 94.706 & -28.75 & -17.25 & -5.75 & 5.75 & 17.25 & 28.75 \\
\hline 13 & 118.497 & -30 & -16 & -2 & 2 & 16 & 30 \\
\hline 14 & 142.996 & -30 & -16 & -2 & 2 & 16 & 30 \\
\hline 15 & 166.996 & -30 & -16 & -2 & 2 & 16 & 30 \\
\hline 16 & 196.997 & -30 & -15.75 & -2 & 2 & 15.75 & 30 \\
\hline 17 & 216.016 & -30 & -15.75 & -2 & 2 & 15.75 & 30 \\
\hline 18 & 237.408 & -30 & -15.75 & -2 & 2 & 15.75 & 30 \\
\hline 19 & 256.063 & -30 & -15.5 & -6 & 6 & 15.5 & 30 \\
\hline 20 & 273.064 & -30 & -15.5 & -6 & 6 & 15.5 & 30 \\
\hline 21 & 294.406 & -30 & -15.5 & -6 & 6 & 15.5 & 30 \\
\hline 22 & 322.262 & -30 & -18 & -6 & 6 & 18 & 30 \\
\hline 23 & 346.138 & -30 & -18 & -6 & 6 & 18 & 30 \\
\hline 24 & 370.015 & -30 & -18 & -6 & 6 & 18 & 30 \\
\hline 25 & 393.49 & -30 & -18 & -6 & 6 & 18 & 30 \\
\hline 26 & 418.456 & -30 & -18 & -6 & 6 & 18 & 30 \\
\hline
\end{tabular}

\section{Bleed System Instrumentation}

The bleed system was instrumented to measure the pressure, temperature, and flow rate in each of the 6 bleed regions. The bleed box had a steady-state static pressure measurement and a high frequency response pressure measurement in each region. Each bleed line had a total of three static pressure measurements: one each in the 16 inch, 12 inch and 8 inch pipes. Additionally, each bleed line had a thermocouple in the 8 inch lines. The flow rate in the 8 inch lines was measured using multi-port pitot tube flow meters. The flow rate was not measured in the 12 inch lines.

\section{Transonic Array}

The same transonic array used for previous calibrations of the 8x6 SWT test section was used to make flow property measurements in the modified test section. The transonic array spans the width of the wind tunnel with 11 equally spaced pressure probes. Six of the probes are pitot-static probes and the remaining five are five-hole flow angularity probes. Arrayed 1.75 in below the pressure probes are 11 thermocouples with the same spacing. A 
photograph of the transonic array installed in the tunnel is shown in Fig. 10, and a schematic of the probe layout is shown in Fig. 11. More details on the previous calibrations and the transonic array can be found in the reports by Arrington ${ }^{12-14}$.

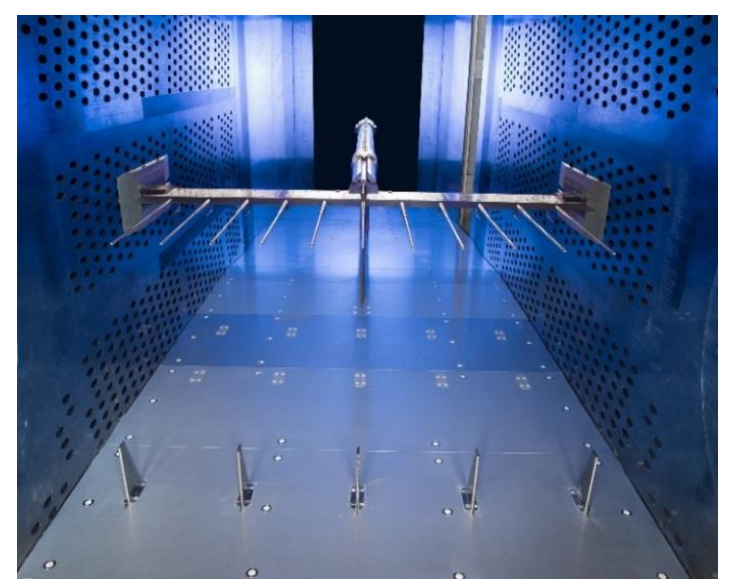

Figure 10. Photograph of the transonic array.

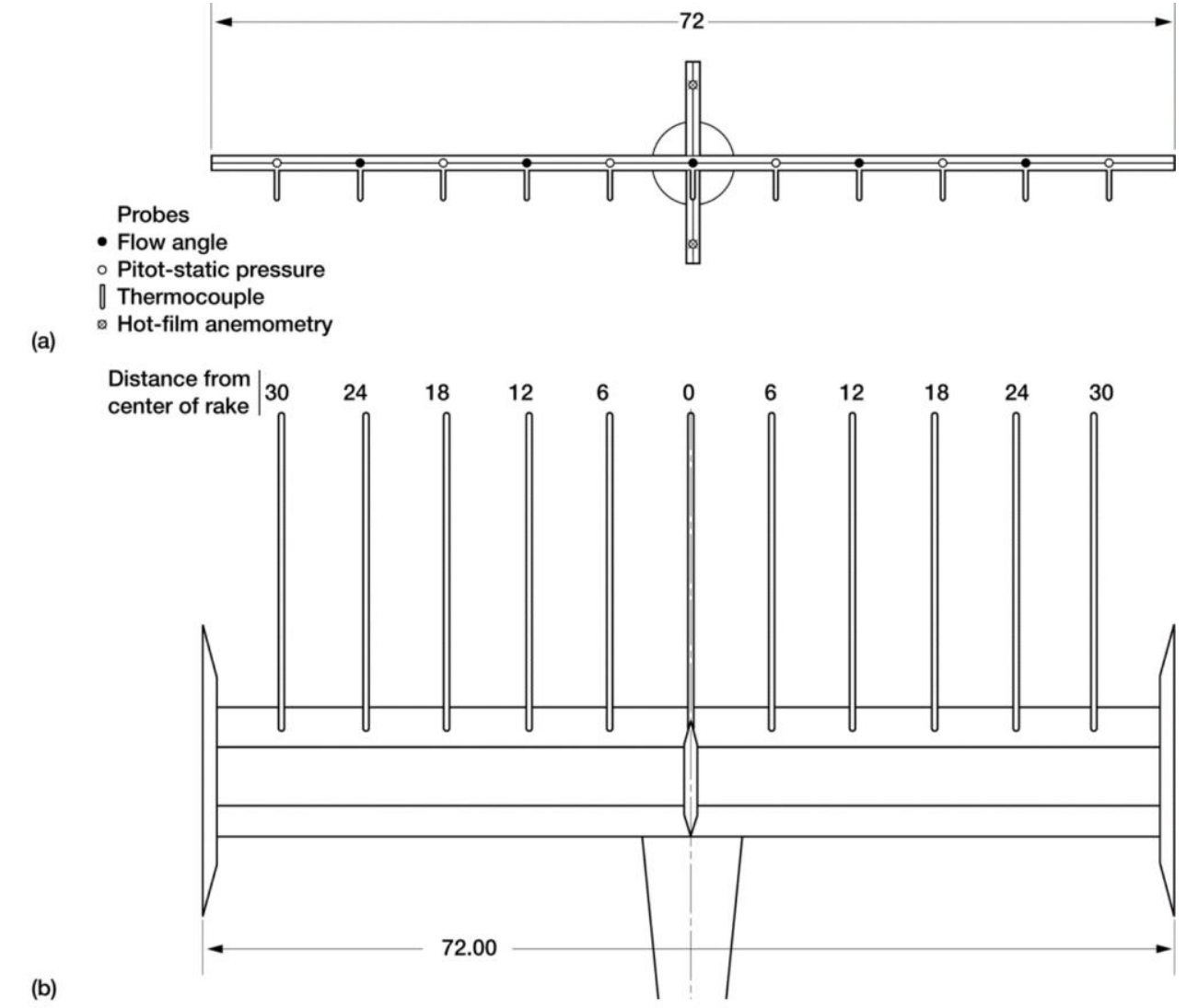

Figure 11. Instrumentation layout of transonic array. (a) Downstream view. (b) Plan view. All dimensions are inches. 


\section{Boundary Layer Rakes}

Two types of boundary layer rakes were used during the test. Three existing rakes were used to measure the total pressure in the boundary layer on the tunnel sidewalls and ceiling at the same axial station as the transonic array. Each rake had 25 total pressure probes with the probe distribution shown in Table 3, and a photograph of the ceiling and wall rake type is shown in Fig. 12.

Five new boundary layer rakes, shown in Fig. 13, were built to measure the total pressure in the boundary layer along the raised floor. Each rake had 18 total pressure probes with the probe distribution shown in Table 3 .

Pockets in the raised floor panels allowed the rakes to be installed at five different axial stations, three of which were used during this test. At each axial station, the five rakes were arrayed 14 inches apart with the third or middle rake on the tunnel centerline.

Table 3. Probe Distribution for the Boundary Layer Rakes.

\begin{tabular}{|c|c|c|}
\hline & \multicolumn{2}{|c|}{ Probe Distance from the Wall, in } \\
\hline & Ceiling and Wall Rakes & Raised Floor Rakes \\
\hline 1 & 0.25 & 0.046 \\
\hline 2 & 0.5 & 0.139 \\
\hline 3 & 0.75 & 0.279 \\
\hline 4 & 1 & 0.464 \\
\hline 5 & 1.25 & 0.696 \\
\hline 6 & 1.5 & 0.975 \\
\hline 7 & 2 & 1.300 \\
\hline 8 & 2.25 & 1.671 \\
\hline 9 & 3 & 2.089 \\
\hline 10 & 3.5 & 2.554 \\
\hline 11 & 4 & 3.064 \\
\hline 12 & 4.5 & 3.621 \\
\hline 13 & 5.5 & 4.225 \\
\hline 14 & 6.5 & 4.875 \\
\hline 15 & 7.5 & 5.571 \\
\hline 16 & 8.5 & 6.314 \\
\hline 17 & 9.5 & 7.104 \\
\hline 18 & 10.5 & 7.939 \\
\hline 19 & 11.5 & -- \\
\hline 20 & 12.5 & -- \\
\hline 21 & 13.5 & -- \\
\hline 22 & 14.5 & -- \\
\hline 23 & 15.5 & -- \\
\hline 24 & 16.5 & -- \\
\hline 25 & 17.5 & -- \\
\hline
\end{tabular}




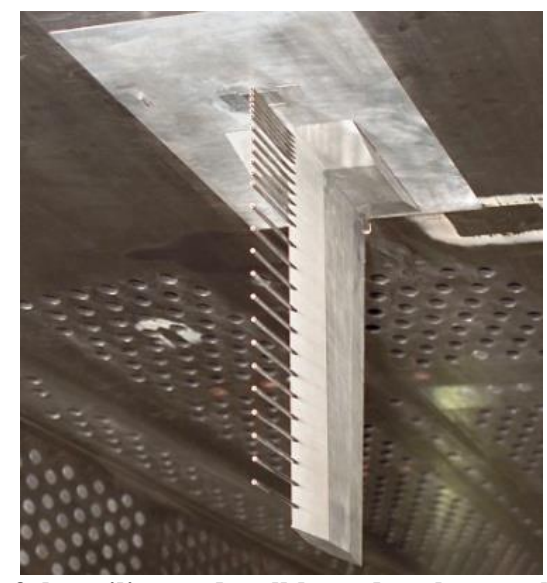

Figure 12. Photograph of one of the ceiling and wall boundary layer rakes installed in the wind tunnel.

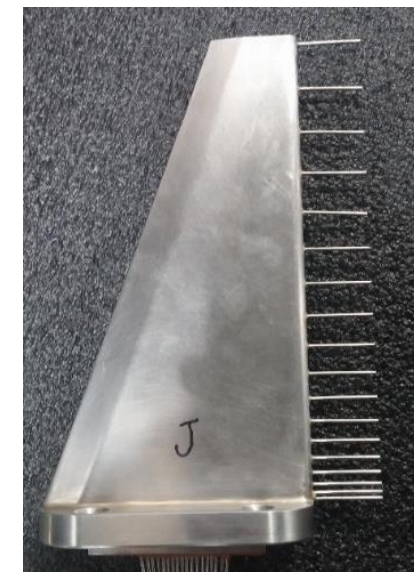

Figure 13. Photograph of one of the raised floor boundary layer rakes.

\section{E. Test Conditions and Configurations}

Data were collected over a range of test conditions with the intent to cover the range of conditions of interest for the propulsor test. The Mach number was varied from 0.55 to 0.88 , however this paper will show results only for the design Mach number of 0.78 .

Raised floor bleed was tested both for cases with equal bleed flow rate in each region and cases with varying flow rate across the width of the tunnel to attempt to achieve a uniform boundary layer thickness across the tunnel. For the equal bleed rate cases, mass flow rate was varied in $1 \mathrm{lbm} / \mathrm{s}$ increments up to $5 \mathrm{lbm} / \mathrm{s}$ in each line for a total of 30 $\mathrm{lbm} / \mathrm{s}$ across the six lines. Additionally the 8 in lines were fully opened, which provided approximately $5.6 \mathrm{lbm} / \mathrm{s} \mathrm{per}$ line or a total of $33.5 \mathrm{lbm} / \mathrm{s}$. The effect of fully opening the 12 in bleed lines was also investigated. Due to facility limitations, when the 12 in lines were opened the 8 in lines had to be closed. The boundary layer was also varied during the test by switching out the boundary layer thickening pins of different heights. Three pin configurations were tested: no pins, 2.00 in pins, and 2.75 in pins.

Measurements were taken with the transonic array at three axial and four vertical stations, with a total of seven locations tested. Generally the boundary layer rakes were installed at or near the axial location of the transonic array. If the transonic array was at either of the lower two vertical positions, the ceiling and wall boundary layer rakes were installed and the raised floor boundary layer rakes were removed. If the transonic array was in either of the higher two vertical positions, the raised floor boundary layer rakes were installed and the ceiling and wall rakes were removed. This was done to allow adequate spacing between the transonic array and the boundary layer measurements. The locations where the transonic array and boundary layer rakes were installed during the test are shown in Fig. 14 with the colored numbers indicating the run during which each position was used. 


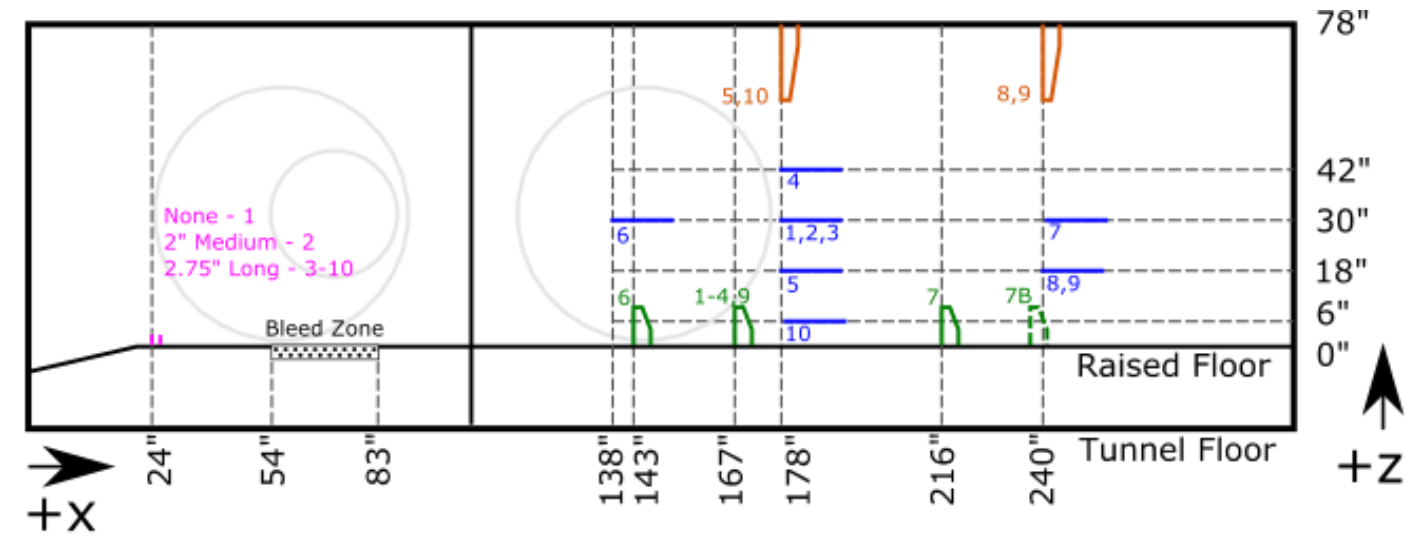

Key: "Pins || Ceiling/Wall Rakes _-Transonic Array I Floor Rakes

Figure 14. Schematic showing the locations where the test hardware was installed. Colored numbers indicate the run numbers for which each position was used.

\section{Results}

\section{A. Raised Floor Boundary Layer Development}

In order to determine which boundary layer thickening pins would provide the required boundary layer thickness entering the inlet during the embedded propulsor test, a limited amount of data was collected for three pin configurations: no pins, 2.00 in pins, and 2.75 in pins. It can be seen in Fig. 15 that without bleed all of the configurations resulted in thick boundary layers with large variations in boundary layer thickness across the span of the tunnel. The center three rake measurements cover a region representative of the inlet inflow for the propulsor test. Looking at the calculated boundary layer thickness for the central region covered by these three rakes from $y=-14$ in to $y=14$ in, there is a lateral variation of 0.62 in with no pins, 0.52 in with the $2.00 \mathrm{in}$ pins, and 1.50 in for the 2.75 in pins.

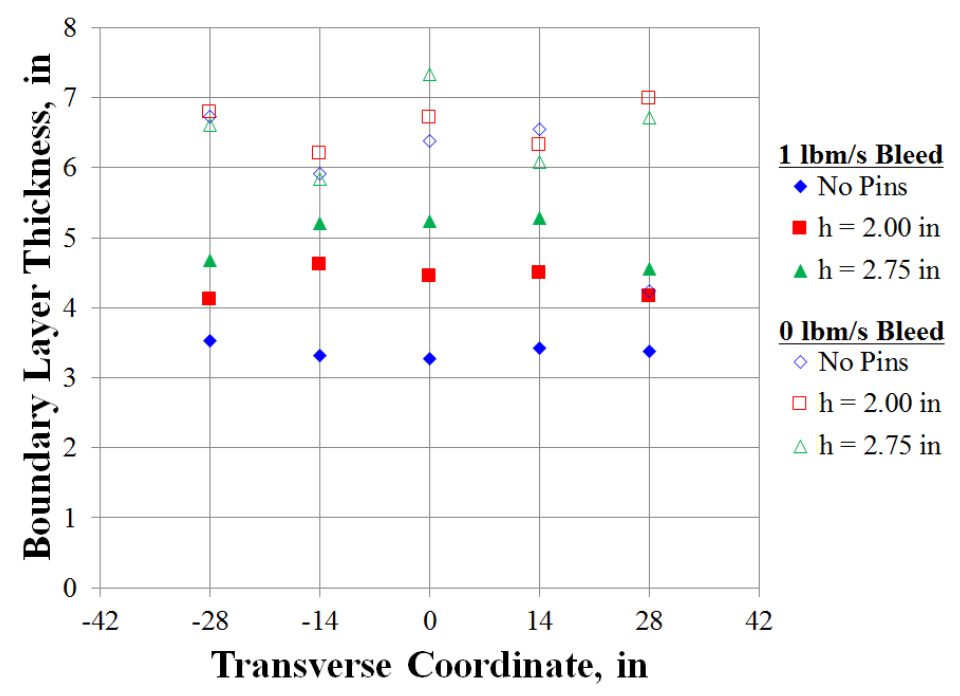

Figure 15. Effect of the pins on the boundary layer thickness at tunnel station 167. Shown for both no raised floor bleed and raised floor bleed at $1 \mathrm{lbm} / \mathrm{s}$ in each of the six bleed regions.

To enable testing the sensitivity of the propulsor to changes in boundary layer thickness, the ideal pins would have a boundary layer thickness larger than the desired 4.8 in design boundary layer thickness with the minimum controllable raised floor bleed flow rate. For the raised floor bleed system, the minimum controllable bleed flow rate 
was $1.0 \mathrm{lbm} / \mathrm{s}$. With this minimum bleed flow rate, it can be seen that the boundary layer thicknesses are decreased by 2-3 in for each pin configuration. The boundary layer thickness was also more uniform over the central range of the tunnel with a lateral variation of 0.15 in for no pins, 0.16 in for 2.00 in pins, and 0.08 in for 2.75 in pins. Without pins, the average boundary layer thickness for the center three rakes was $3.33 \mathrm{in}$. For 2.00 in pins the average was 4.52 in. For 2.75 in pins the average was 5.07 in. Only these longest pins provided a boundary layer thickness for the minimum bleed flow rate that was thicker than the desired design boundary layer thickness (i.e. 4.8 in), so the remainder of the testing was done with the 2.75 in pins.

The effects of the bleed flow rate on the raised floor boundary layer thickness with the 2.75 in pins are shown in Fig. 16. As in the previous figure it can be seen that with raised floor bleed there is little lateral variation in boundary layer thickness over the center three boundary layer rakes. As the bleed flow rate was increased the boundary layer thickness smoothly decreased at an average rate of $0.32 \mathrm{in} /(\mathrm{lbm} / \mathrm{s})$. With the 8 in lines, the thinnest boundary layer thickness that could be achieved in the central region of the wind tunnel was $3.71 \mathrm{in.}$ With only the $12 \mathrm{in} \mathrm{lines} \mathrm{open,}$ the boundary layer thickness could be reduced to $1.31 \mathrm{in}$.

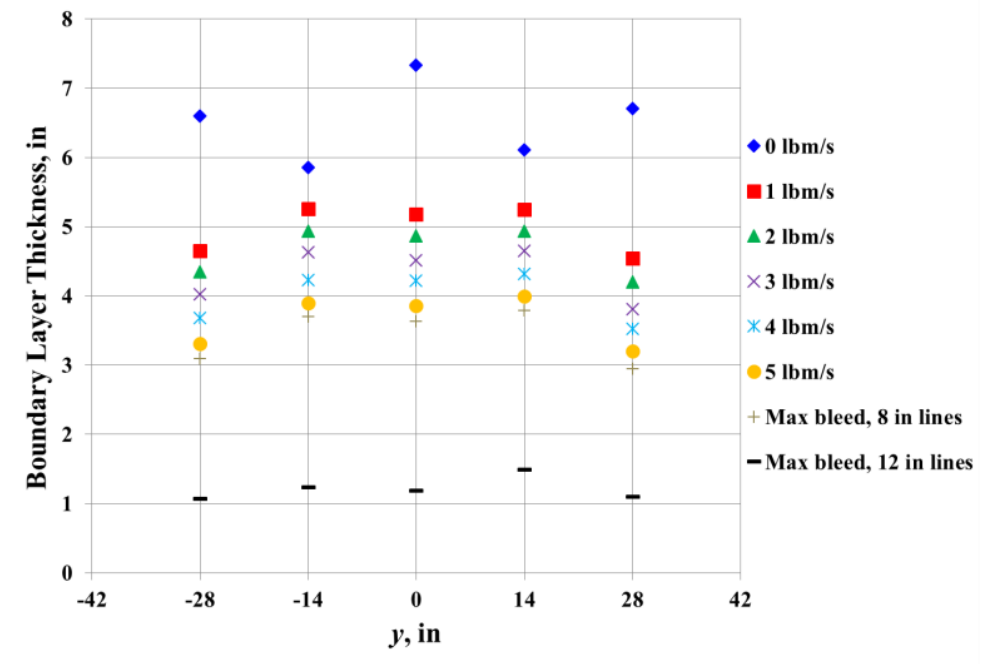

Figure 16. Effect of raised floor bleed flow rate on the boundary layer thickness at tunnel station 167.

It can also be observed that the boundary layer thickness measured by the rakes nearest the tunnel sidewalls were thinner than the center three. This is likely due to the bleed through the porous tunnel sidewalls. For the propulsor test it was desired to have the most uniform boundary layer possible across the span of the raised floor. To achieve this, the raised floor bleed flow rate in the bleed regions along each sidewall were reduced to the minimum controllable flow rate, $1.0 \mathrm{lbm} / \mathrm{s}$, while the center four bleed regions were set to a flow rate of $2.25 \mathrm{lbm} / \mathrm{s}$. The resulting lateral variation in boundary layer thickness is shown in Fig. 17 compared to that for an equal $2.0 \mathrm{lbm} / \mathrm{s}$ bleed in each region. The difference in boundary layer thickness between the center and sidewall regions was reduced from 0.68 in to 0.39 in by adjusting the sidewall bleed regions; however the central region was not affected. The boundary layer thickness at the middle of the tunnel for this uniform bleed condition was 4.82 in. The final set of bleed flow rates selected as the design condition was $2.25 \mathrm{lbm} / \mathrm{s}$ in each of the four center bleed regions, $1.0 \mathrm{lbm} / \mathrm{s}$ in the sidewall region on the negative- $y$ side, and $1.1 \mathrm{lbm} / \mathrm{s}$ in the sidewall region on the positive- $y$ side (denoted as Level BL). The slightly increased bleed flow rate along the positive- $y$ sidewall was due to the fact that decreasing the flow rate any further resulted in undesireable behavior. When the bleed was reduced below this level, the boundary layer thickness for that zone increased close to that measured without any bleed. This behavior was only noted in measurements at $y=28 \mathrm{in}$. The boundary layer profile at the tunnel centerline resulting from this set of bleed conditions is shown in Fig. 18. The boundary layer profile measured in the test was slightly fuller than the profile from the external vehicle CFD near the wall. 


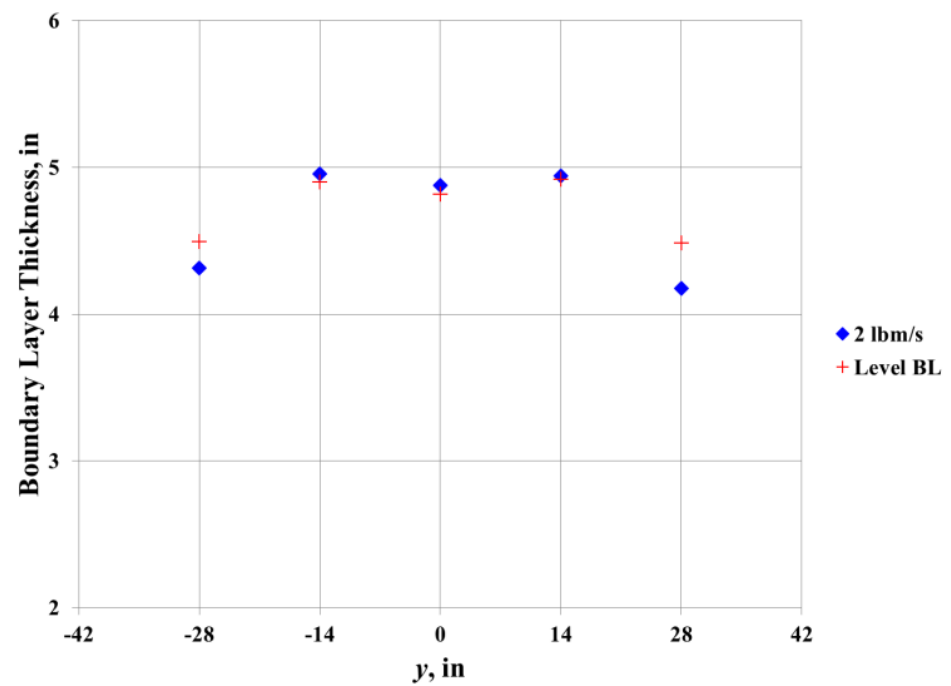

Figure 17. Comparison of equal bleed flow for each bleed region to the final bleed flow distribution selected for the level boundary layer design point.

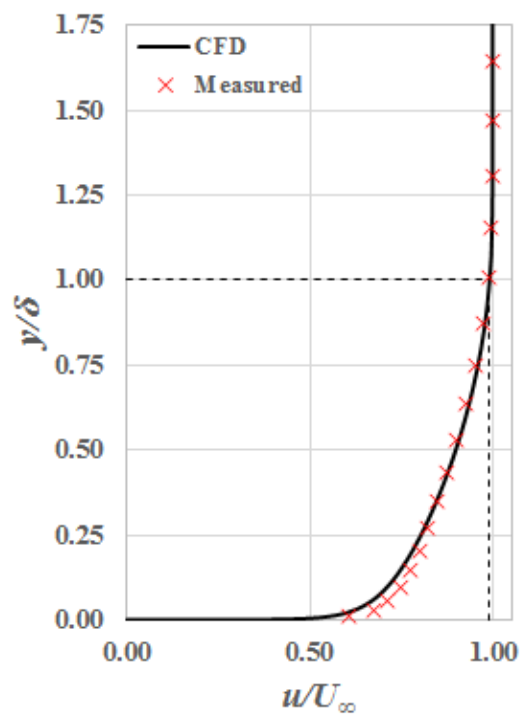

Figure 18. Comparison of boundary layer profiles from the external vehicle CFD to the profile measured along the tunnel centerline at tunnel station 167.

While the axial station at which the measured boundary layer was compared to the boundary layer from the vehicle CFD was $x=176$ in, the inlet lip in the embedded propulsor test was farther downstream at $x=228$ in. Therefore, the axial growth rate of the boundary layer was of interest. To determine whether the boundary layer thickening pins and raised floor bleed had an undesired effect on the growth of the boundary layer axially, the boundary layer thickness measured in the experiment was compared to the expected compressible boundary layer growth as described by Tucker ${ }^{15,16}$. The boundary layer thickness measured at tunnel station 167 was used to determine the equivalent length of flat plate that would be required to achieve the measured thickness. Then, the distances between the measurement stations were subtracted or added from that equivalent length to calculate the thickness at the upstream or downstream tunnel station respectively. The resulting comparison is shown in Fig. 19. The boundary layer growth rate measured in the experiment is only slightly greater than theory would predict. 


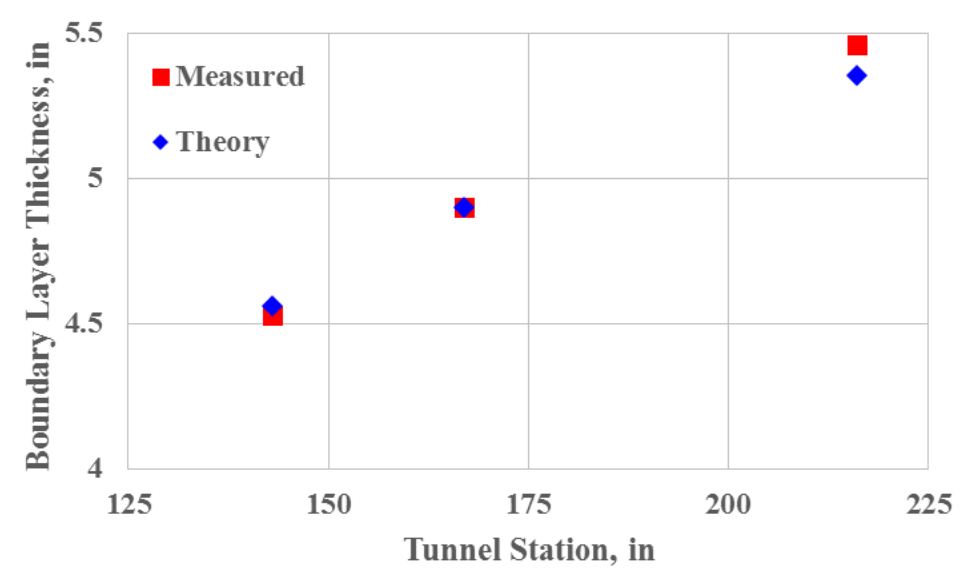

Figure 19. Comparison of measured growth rate of the boundary layer thickness to theory.

\section{B. Characterization of the Freestream Flowfield}

In addition to the boundary layer development along the raised floor, the uniformity of the freestream flowfield was of interest. Flow property measurements from the transonic array at a vertical position of $z=30$ in and the uniform boundary layer bleed settings for three axial locations are shown in Fig. 20, with the pressures and temperatures normalized by the respective bellmouth-rake values. Approximate scales in non-normalized dimensions are shown in the lower right corner of Figures 20 (a), (b) and (e), based on average bellmouth conditions across the cases. It can be seen that there is little variation in total pressure axially along the tunnel. Among the center seven probes, which are outside of any wall effects, the largest difference is at $y=12$ in with a difference of 0.005 psi, which is within the uncertainty of the instrumentation.

In the static pressure plot a saw tooth pattern can be observed. This is because the static pressure at stations $y=-$ $30,-18,-6,6,18$, and 30 are measured by pitot-static probes, while the static pressure at stations $y=-24,-12,0,12$, and 24 are measured by flow angularity probes. The average difference in pressure based on probe type is $0.034 \mathrm{psi}$. There is little difference in the static pressure between the first two axial stations, but at the third station the static pressure is lower indicating an elevated Mach number in the core of the freestream flowfield.

The flow angles in both the pitch and yaw directions are small at all three axial stations, with maximum amplitudes in pitch of $0.55^{\circ}$ and $0.69^{\circ}$ in yaw. For the pitch direction, the angles are generally smallest at the first axial station.

It can be seen in Fig. 20(e) that the total temperature gradient along each sidewall extends from the outer measurements at $y= \pm 30$ in all the way to approximately $y= \pm 12$ in. In the central region the temperature is more uniform with a small dip of about $0.25 \mathrm{R}$ at the tunnel centerline. There is little change in this profile at the three axial stations.

Figure 21 shows the same set of plots for tunnel station 178 with the uniform boundary layer bleed settings for four array heights. Looking at the total and static pressure, there is more scatter for the array height of $z=6$ in which is near the edge of the boundary layer. Additionally, the total pressures are lower and the static pressures are higher than for the other array heights indicating lower speed flow. At the higher array positions, the measured profiles are more uniform with $\mathrm{z}=30$ in and 42 in being the most alike.

The flow angles for the different array heights are slightly higher than were seen previously, but are still under $1^{\circ}$.

Looking at the total temperature plot, it should first be noted that two of the measurements are missing for the $z$ $=6$ in position. Because of the design of the transonic array, the thermocouple at $y=0$ in had to be removed to install the array this close to the raised floor. The thermocouple at $y=24$ in was giving bad readings during the run in which these data were acquired. Even so, it can be seen that the total temperature was most uniform in the transverse direction at this $z=6$ in location and that there is increasing curvature as the array is moved farther from the raised floor. There is also a clear vertical gradient in temperature with cooler air near the raised floor. The working theory regarding the source of this gradient is that uninsulated portions of the wind tunnel walls upstream of the test section region were allowing heat to be lost and a larger-than-expected thermal gradient to develop. This gradient will be ingested into the inlet during the embedded propulsor test, and needs to be taken into account for the calculation of fan efficiency. For low pressure ratio fans, like the one designed for this boundary-layer-ingestion application, calculated adiabatic efficiency is very sensitive to changes in temperature. 


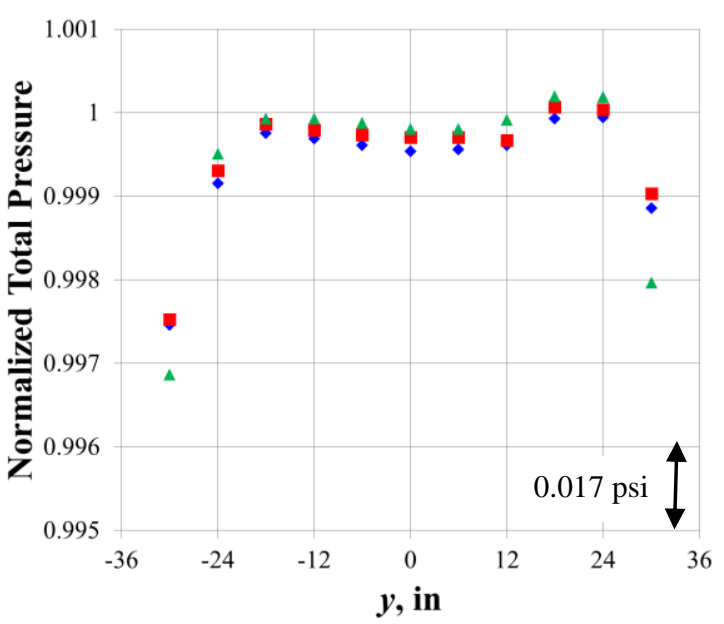

(a)

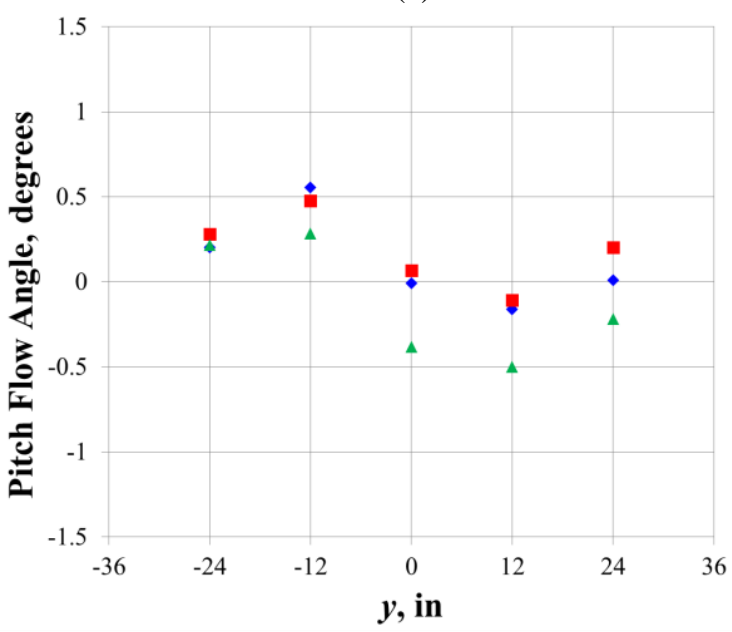

(c)

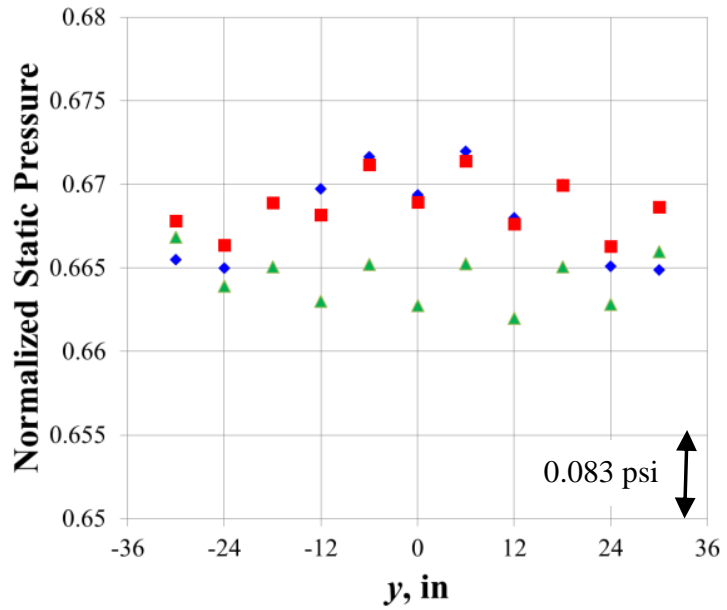

(b)

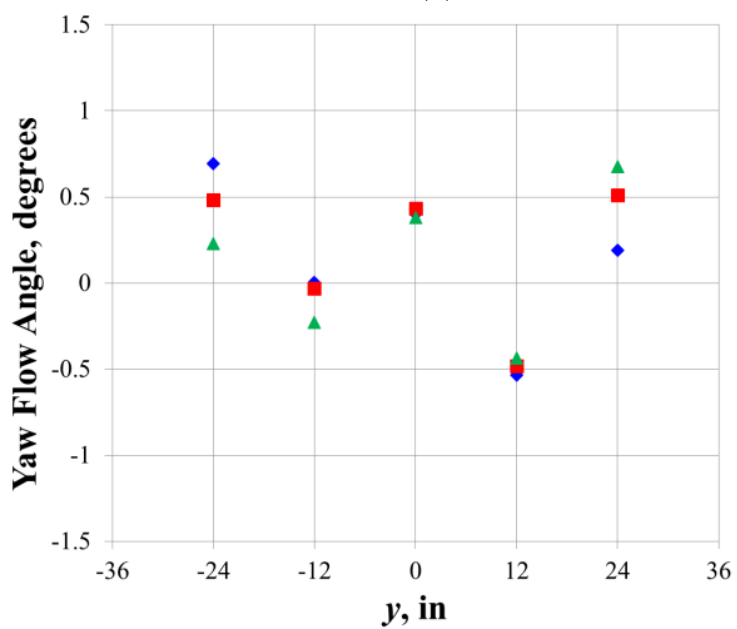

(d)

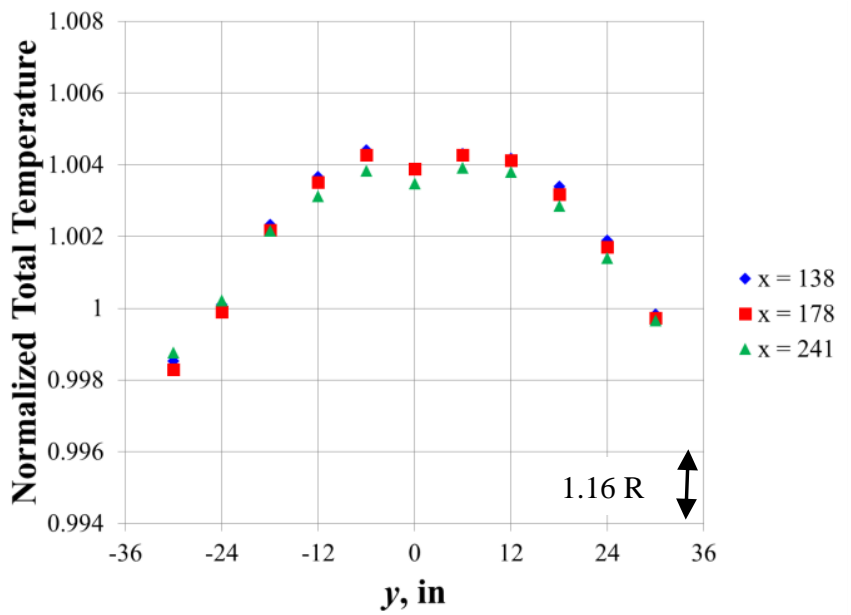

(e)

Figure 20. Transonic array measurements at $z=30$ in for three axial locations. (a) Total pressure normalized by bellmouth total. (b) Static pressure normalized by bellmouth total. (c) Pitch angle measured by 5-hole flow angularity probe. (d) Yaw angle measured by 5-hole flow angularity probe. (e) Total temperature normalized by bellmouth total temperature. 


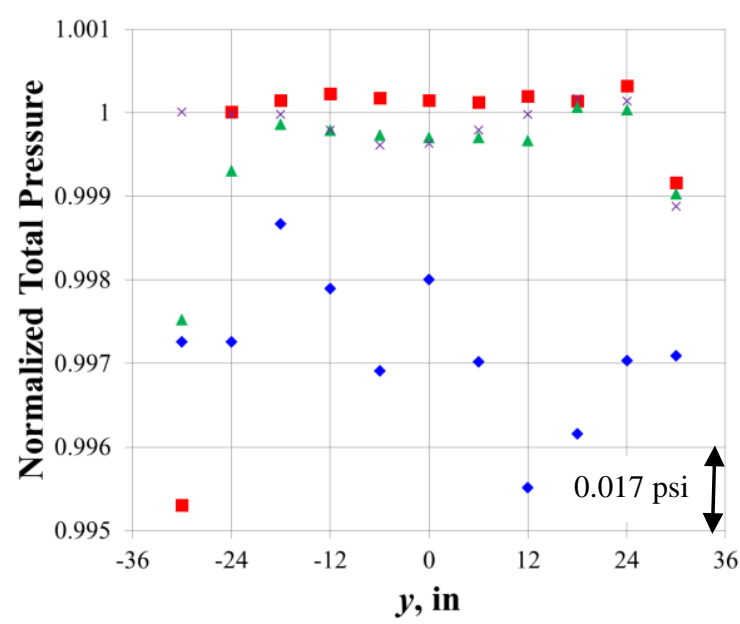

(a)

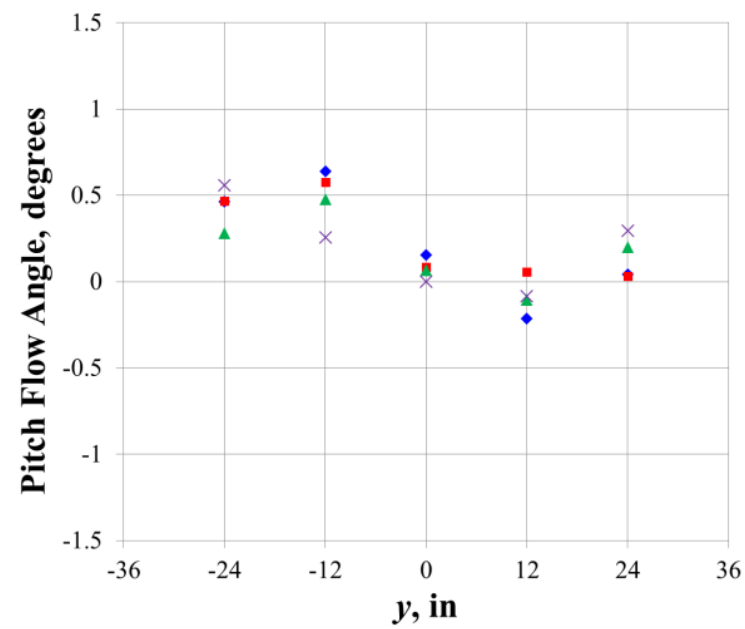

(c)
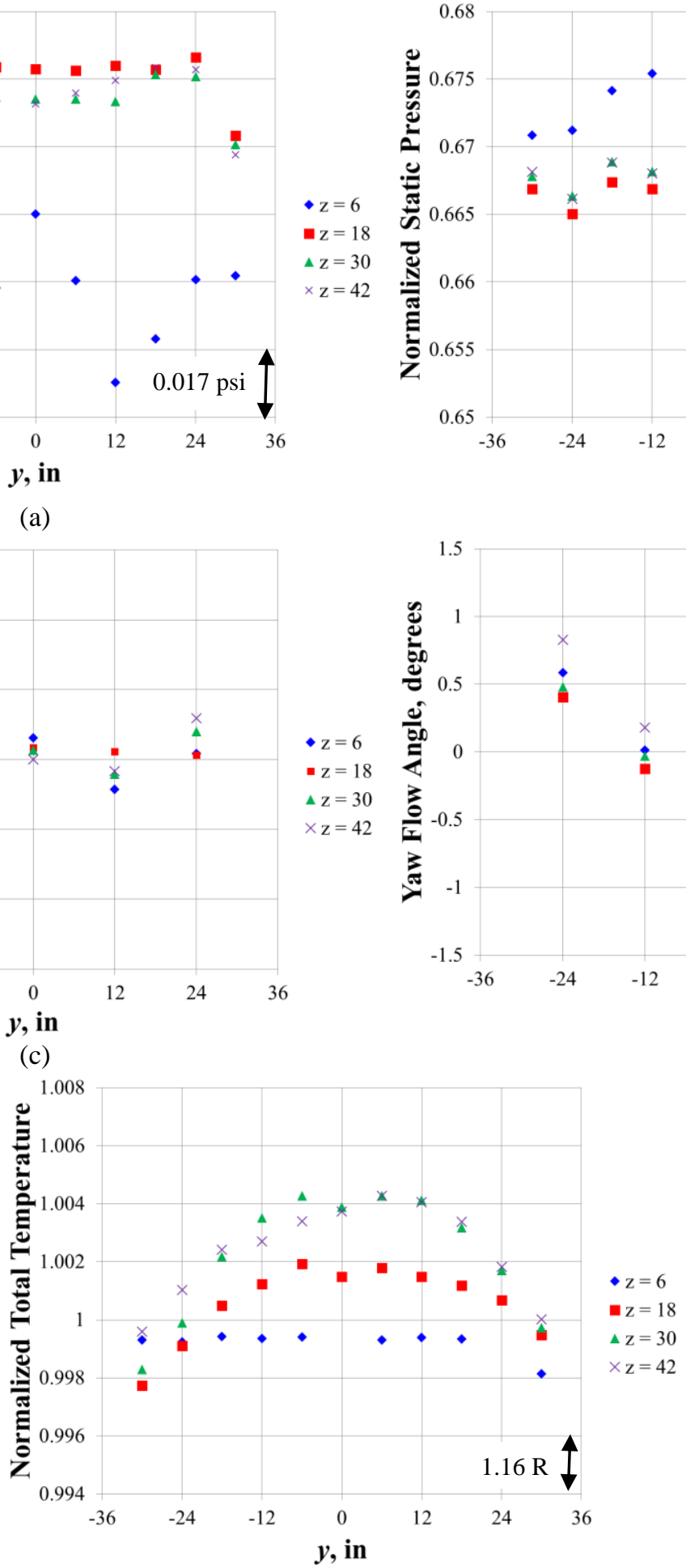

(e)

\section{)}

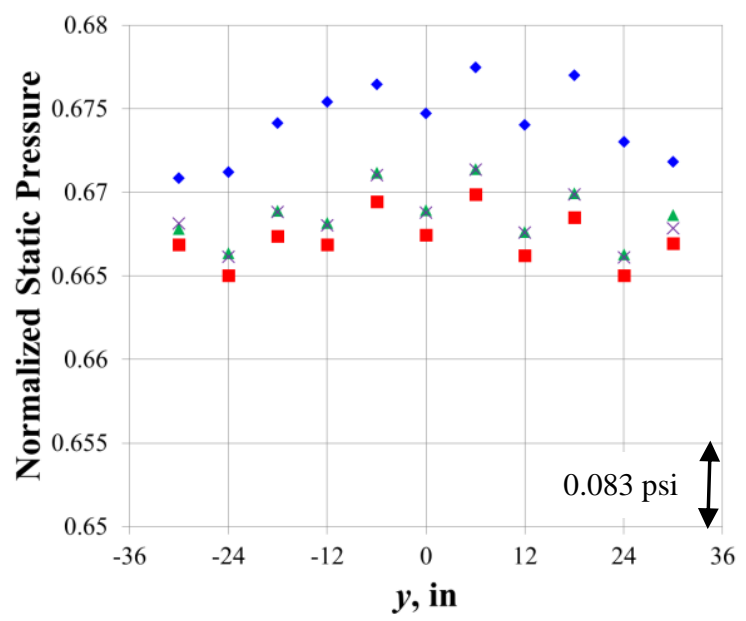

(b)

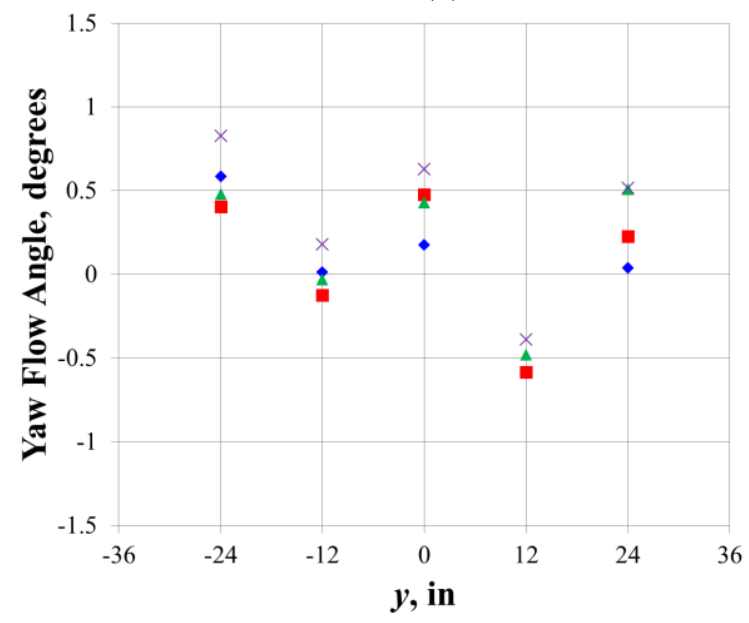

(d)

Figure 21. Transonic array measurements at tunnel station 178 for four transonic array heights. (a) Total pressure normalized by bellmouth total. (b) Static pressure normalized by bellmouth total. (c) Pitch angle measured by 5-hole flow angularity probe. (d) Yaw angle measured by 5-hole flow angularity probe. (e) Total temperature normalized by bellmouth total temperature. 


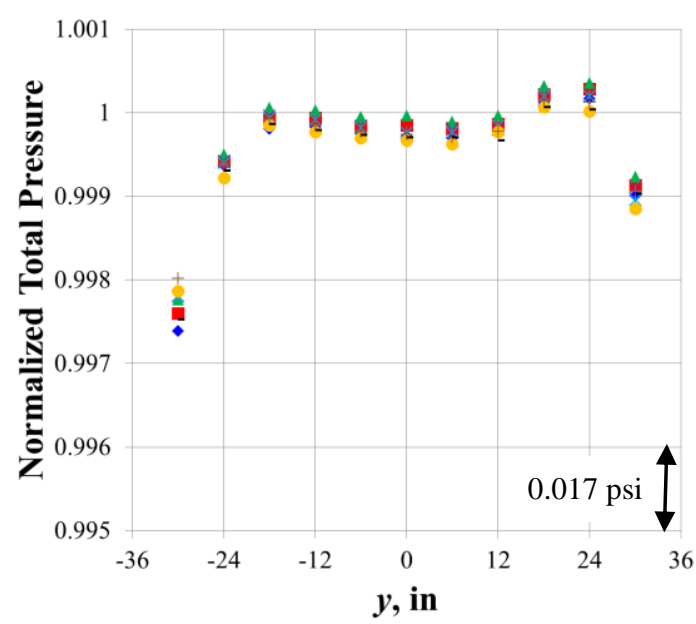

(a)

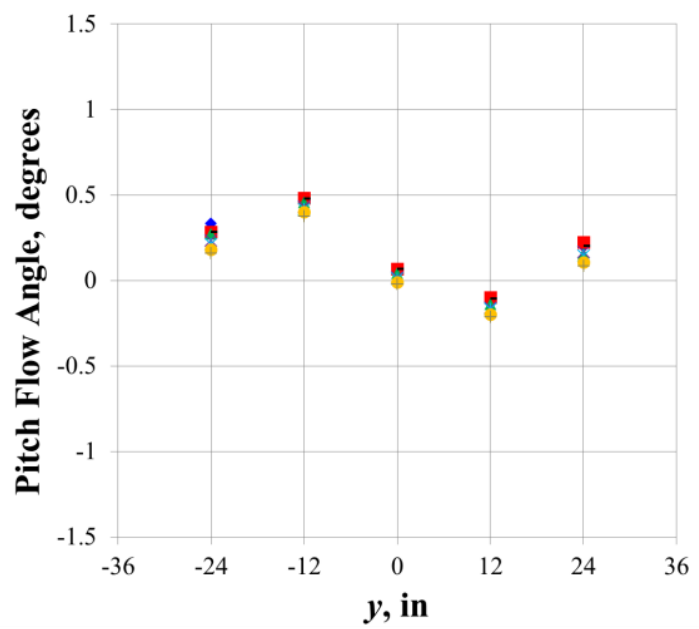

(c)

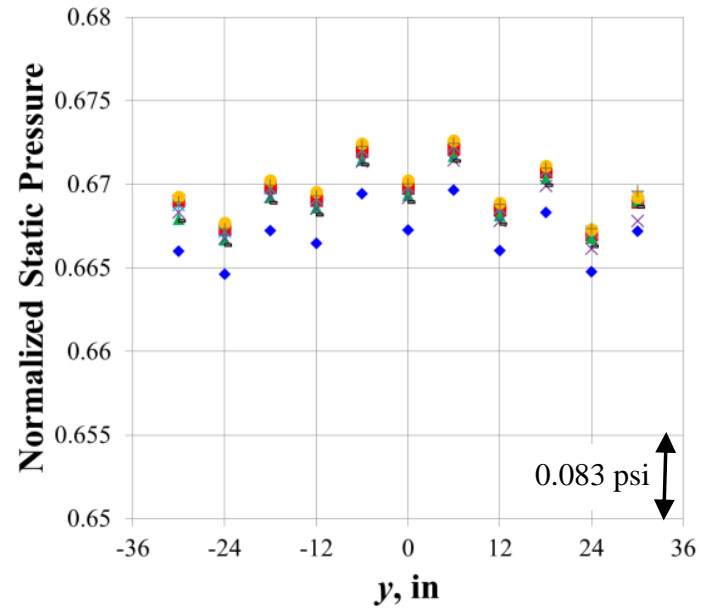

(b)

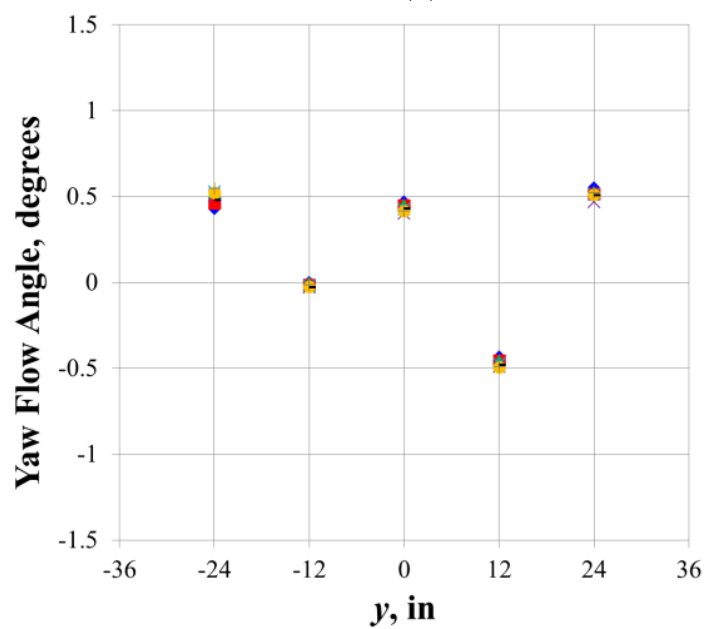

(d)

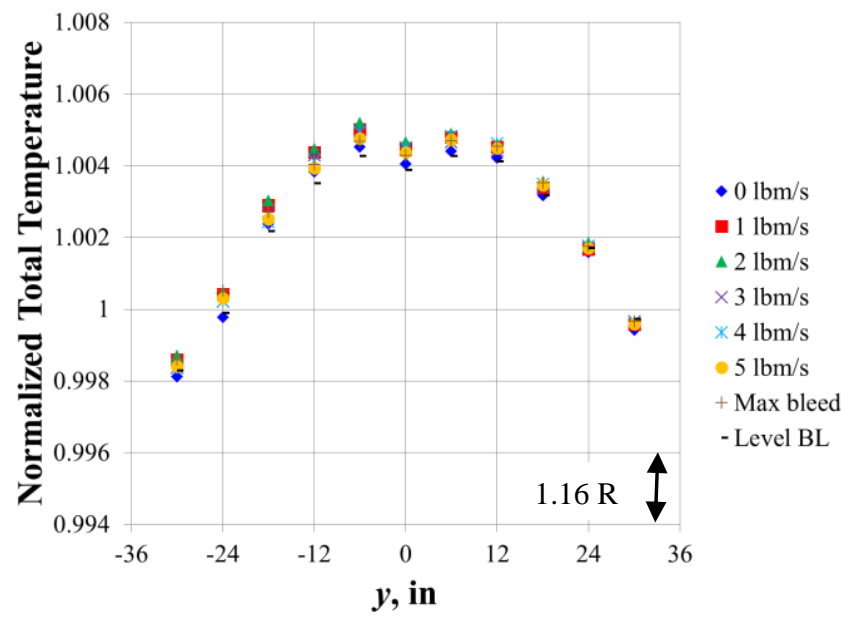

(e)

Figure 22. Transonic array measurements at tunnel station 178, $z=30$ in varying bleed flow rates. (a) Total pressure normalized by bellmouth total. (b) Static pressure normalized by bellmouth total. (c) Pitch angle measured by 5-hole flow angularity probe. (d) Yaw angle measured by 5-hole flow angularity probe. (e) Total temperature normalized by bellmouth total temperature. 
The effect of the raised floor bleed flow rate on the measured freestream flow properties is shown in Fig. 22 with the array located at tunnel station $178, z=30$ in. The small differences in each of the flow properties seen with changes in raised floor bleed flow rate are within the sensitivities of the transducers, indicating that the raised floor bleed flow does not affect the tunnel freestream flowfield.

The static pressures measured along the raised floor are shown in Fig. 23, with the line numbers in the legend equivalent to the line numbers in Table 2. The effect of several features of the test hardware on the static pressure can be clearly seen, including the curved transition panels and the bleed region, which are indicated in the figure. The similarity in the static pressure for each line indicates that the static pressure is uniform across the width of the tunnel. The static pressure along the flat section of the raised floor between the end of the bleed box and the aft transition panel is relatively constant and corresponds to a range of Mach numbers based on total pressures measured by the bellmouth rakes of 0.776 to 0.793 in that region. This is in good agreement with the target test Mach number of 0.78 .

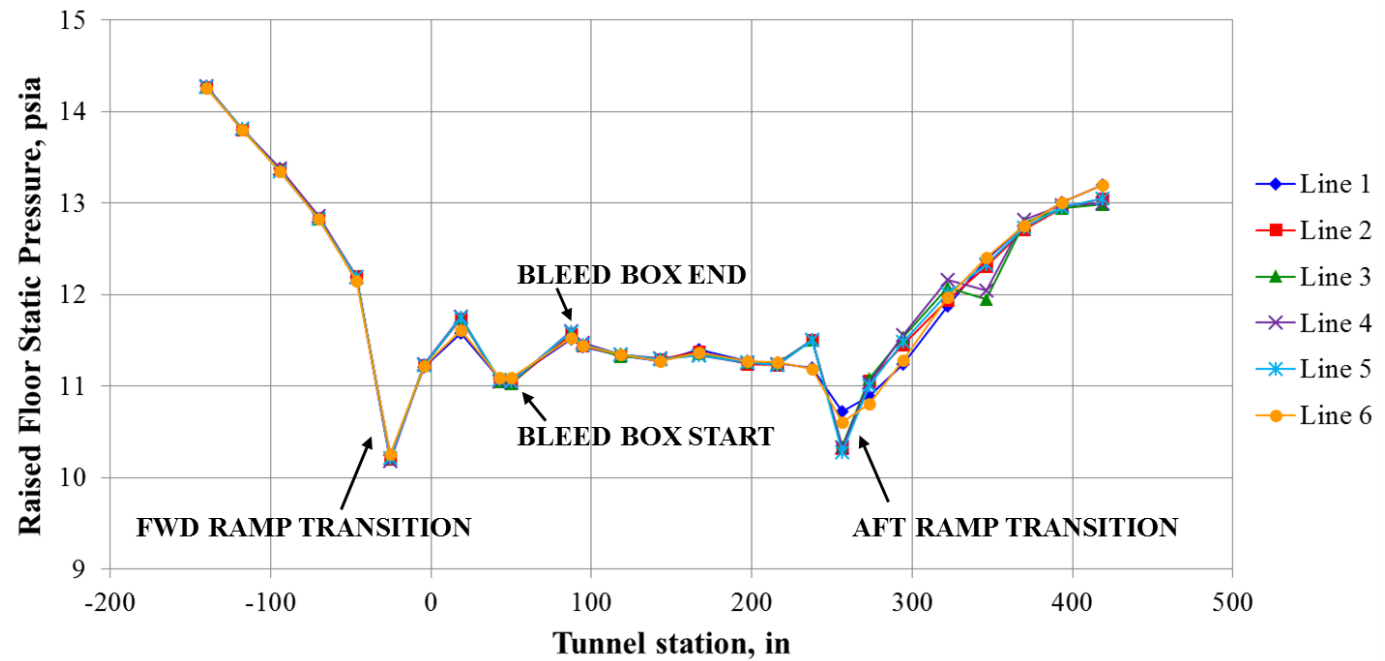

Figure 23. Static Pressures measured along the raised floor.

\section{Summary}

The potential for large reductions in fuel burn has driven interest in boundary layer ingesting propulsion. The Boeing N2A-exte vehicle configuration was selected as a representative platform. Computational fluid dynamics of the external vehicle surface was used to define the desired inflow boundary layer and freestream conditions. An embedded propulsor was designed for these distorted flow conditions and tested in the 8-Foot by 6-Foot Supersonic Wind Tunnel.

Modifications to the tunnel test section were required in order to simulate the flowfield including a raised false floor, boundary layer thickening pins, and a bleed system. These extensive changes required a new calibration of the modified tunnel test section prior to testing the propulsor. The testing showed that a combination of boundary layer thickening pins and raised floor bleed was able to provide the target boundary layer thickness with margin for thickness sensitivity studies. A comparison of the measured boundary layer profile to the profile from the external vehicle CFD showed good agreement with only a slightly fuller profile in the near wall region in the experiment. The boundary layer growth that was measured axially was consistent with theory.

The freestream measurements were set to match the desired conditions at the centerline of the tunnel. Measurements from the transonic array showed that the total and static pressure were relatively uniform across the central region of the tunnel. The flow angles were small for the both the pitch and yaw direction. There was a larger than anticipated gradient in total temperature across both the spanwise and vertical directions that will add a level of complexity to the efficiency calculations for the propulsor test.

The measured conditions were deemed sufficiently representative of the reference flowfield to proceed to the propulsor test. Calibration curves were developed on the basis of this data to guide setting conditions during the embedded propulsor test entry. 


\section{Acknowledgements}

This effort was supported by NASA's Advanced Air Transport Technology Project. The authors gratefully acknowledge the support of the many additional people who made this work possible: the 8x6 SWT facility staff and our team members at UTRC and Arnold Engineering Development Complex.

\section{References}

1 R. T. Kawai, D. L. Friedman and L. Serrano, "Blended Wing Body (BWB) Boundary Layer Ingestion (BLI) Inlet Configuration and System Studies," NASA/CR 214534, 2006.

2 J. R. Welstead and J. L. Felder, "Conceptual Design of a Single-Aisle Turboelectric Commercial Transport with Fuselage Boundary Layer Ingestion," in 54th AIAA Aerospace Sciences Meeting, San Diego, California, 2016, AIAA-2016-1027.

3 M. Drela, "Development of the D8 Transport Configuration," in 29th AIAA Applied Aerodynamics Conference, Honolulu, Hawaii, 2011, AIAA-2011-3970.

4 L. W. Hardin, G. Tillman, O. P. Sharma, J. Berton and D. J. Arend, "Aircraft System Study of Boundary Layer Ingesting Propulsion," in 48th AIAA/ASME/SAE/ASEE Joint Propulsion Conference, Atlanta, Georgia, 2012, AIAA-2012-3993.

5 D. J. Arend, G. Tillman and W. F. O'Brien, "Generation After Next Propulsor Research: Robust Design for Embedded Engine Systems," in 48th AIAA/ASME/SAE/ASEE Joint Propulsion Conference, Atlanta, Georgia, 2012, AIAA-2012-4041.

6 M. A. Bakhle, T. S. R. Reddy, G. P. Herrick, A. Shabbir and R. Florea, "Aeromechanics Analysis of a Boundary Layer Ingesting Fan," in 48th AIAA/ASME/SAE/ASEE Joint Propulsion Conference, Atlanta, Georgia, 2012, AIAA-2012-3995.

7 R. V. Florea, C. Matalanis, L. W. Hardin, M. Stucky and A. Shabbir, "Parametric Analysis and Design for Embedded Engine Inlets," in 48th AIAA/ASME/SAE/ASEE Joint Propulsion Conference, Atlanta, Georgia, 2012, AIAA-2012-3994.

8 D. J. Arend, J. D. Wolter, S. M. Hirt and A. J. Provenza, "Experimental Evaluation of the Performance and Operability of a Large-Scale Boundary Layer Ingesting Propulsor for Highly Efficient Subsonic Cruise Aircraft," to be presented at Propulsion and Energy Forum, Atlanta, Georgia, 2017.

9 R. H. Soeder, "NASA Lewis 8- By 6-Foot Supersonic Wind Tunnel User Manual," NASA/TM 105771, 1993.

10 L. J. Otten III and J. T. Van Kuren, "Artificial Thickening of High Subsonic Mach Number Boundary Layers," AIAA Journal, vol. 14, no. 11, pp. 1528-1533, Nov 1976.

11 G. Kiel, "Total Head Meter with Small Sensitivity to Yaw," National Advisory Committee for Aeronautics. Technical Memorandum 775, Washington, DC, 1935.

12 E. A. Arrington, M. T. Pickett and R. H. Soeder, "Baseilne Calibration of the NASA Lewis Research Center 8by 6-Foot Supersonic Wind Tunnel (1991 and 1992 Tests)," NASA/TM 97-107431, 1997.

13 E. A. Arrington and J. C. Gonsalez, "Low Speed Calibration of the NASA Lewis Research Center 8- by 6-Foot Supersonic Wind Tunnel (1995 Test)," NASA/CR 198527, 1997.

14 E. A. Arrington, "Calibration of the NASA Glenn 8- by 6-Foot Supersonic Wind Tunnel (1996 and 1997 Tests)," NASA/CR 217270, 2012.

15 M. Tucker, "Approximate Turbulent Boundary-Layer Development in Plane Compressible Flow Along Thermally Insulated Surfaces with Application to Supersonic-Tunnel Contour Correction," NACA TN 2045, 1950.

16 M. Tucker, "Approximate Calculation of Turbulent Boundary-Layer Development in Compressible Flow," NACA TN 2337, 1951. 